\title{
Raceway Design for the Innovative Blast Furnace
}

\author{
Hiroshi NOGAMI, Hideyuki YAMAOKA ${ }^{1)}$ and Kouji TAKATANI" \\ Corporate Research \& Development Laboratories, Sumitomo Metal Industries, Ltd., 1-8 Fuso-cho, Amagasaki, Hyogo \\ 660-0891 Japan. 1) Corporate Research \& Development Laboratories, Sumitomo Metal Industries, Ltd., 16-1 \\ Sunayama, Hasaki-machi, Kashima-gun, Ibaraki 314-0255 Japan.
}

( Received on June 2, 2004; accepted in final form on July 6, 2004)

\begin{abstract}
This study tries to design the combustion zone in the highly efficient blast furnace for aiming at great reduction of energy consumption and environmental loads by use of raceway mathematical model. The model treats strictly the discontinuous movement of lump coke particles inside and around raceway, and it considers heat exchange with gas and chemical reactions with gas.

In this study, first, the verification of the model is performed. Next, the controllability of raceway by blast conditions is investigated. Finally, the raceway in the top gas recycling process is evaluated in terms of the suitability as combustion zone of the novel blast furnace and of the possibility of its realization. The gas recycling process has the characteristic of blowing top gas without $\mathrm{CO}_{2}$, pure oxygen and plastics from tuyere. The results obtained in this work are as follows.

1) Raceway mathematical model has the sufficient ability to represent the characteristics of raceway in all cokes operation and $\mathrm{PCl}$ operation.

2) The shape and size of raceway and gas temperature in raceway can be controlled by blast temperature and gas compositions. In addition, nitrogen enrichment in blast is effective to form the uniform and low temperature combustion zone.

Raceway in top gas recycling process becomes larger, gas temperature in and around raceway is lower and volumetric flow rate of bosh gas is less than conventional process. Therefore, raceway conditions in the recycling process enable high productivity and high efficiency.
\end{abstract}

KEY WORDS: blast furnace; raceway; Discrete Element Method (DEM); mathematical model; nitrogen enrichment; top gas recycling process.

\section{Introduction}

With the rise of the necessity for the energy saving and for the measures against environmental problems in recent years, it is desired to establish the innovative iron-making technology which enables to reduce the amount of energy consumption and $\mathrm{CO}_{2}$ emissions greatly. In this case, it is necessary to perform highly efficient operation under low temperature circumstances, and reducing gas should be supplied efficiently over the whole region inside the blast furnace. Therefore, raceway, a part supplying the gas, has to satisfy the following requirements.

1) Large size

2) Low temperature

3) Fast reaction

Since raceway is one of the most important parts in blast furnace, many researchers have studied until now about the gas flow phenomena within raceway and about the combustion behaviors of pulverized coal inside raceway. ${ }^{1-4)}$ Kuwabara et al. ${ }^{1)}$ developed the 1-dimensional raceway mathematical model and made it possible to predict the distributions of gas temperature and compositions inside raceway. In this model, coke particles within raceway were treated as continuous phase. Additionally the raceway depth and the void fraction inside raceway space were assumed to be constant. Hatano et al. ${ }^{2)}$ and Nogami et al. ${ }^{3)}$ developed the 2-dimensional model by use of the similar approach. Their models calculated not only the atmosphere inside raceway but also the shape and size of raceway. However, they neglected the diameter variation of lump coke particles in gasification. Therefore, their models could not evaluate the size distributions of coke particles inside and around raceway and did not have the ability to express the movement of small coke. In addition, it was essentially difficult to represent the discontinuous behaviors of coke particles as granular materials strictly.

Then, authors have developed the 3-dimensional raceway mathematical model, which used the Discrete Element Method (DEM) as analyzing method of coke movement. ${ }^{5,6)}$ It traces the motion about each lump coke particle existing inside and around raceway. In addition, the heat exchange with gas and the chemical reactions with gas are considered in this model. Moreover, the diameters of coke particles are changed according to gasification. Therefore, the 3-dimensional structure of raceway can be predicted strictly together with the combustion state within raceway.

In this study, first, the outline and verification examples of the raceway mathematical model are shown. Next, aiming at designing the raceway to satisfy the above requirements, the controllability of raceway by adjusting the blast conditions is investigated. Finally, characteristics of raceway in the top gas recycling process are investigated and 
the possibility of its realization in terms of combustion zone appropriate for highly efficient furnace is evaluated.

\section{Mathematical Model}

\subsection{Outline of Mathematical Model}

Three dimensional transient analysis model has been developed. ${ }^{5,6)}$ It is a coupling model of Finite Differencing Method (FDM) and DEM. In this model, the substances within raceway are assumed to be coke, gas, and pulverized coal. On the other hand, since the temperature within raceway is high and the domain can be regarded as dried zone, the existence of liquid is neglected. The treatment of each phase is shown in the following.

\subsubsection{Gas}

1) Gas is compressible viscous fluid and obeys the perfect gas law.

2) Effect of turbulent flow is considered by $k-\varepsilon$ model. ${ }^{7)}$

3) Combustion rate of gas-gas reactions is calculated by eddy dissipation model. ${ }^{8)}$

\subsubsection{Coke}

1) Coke is dispersed particle with sphere shape and the movement is calculated using DEM.

2) Contact force of coke particles is calculated by Voigt Kelvin model. ${ }^{9)}$

3) Gasification rate of coke particles is calculated by shrinking core model, ${ }^{10)}$ in which chemical reaction on the surface of particle, mass transfer in boundary layer, and gas diffusion inside particle are considered.

4) The diameters of respective coke particles become smaller according to the gasification ratio and each coke disappears when its diameter becomes less than one fifth of its initial value.

5) Coke fragments are supposed to exist in packed beds $a$ priori, and the amount of that is determined on the basis of experimental results.

\subsubsection{Pulverized Coal}

1) Pulverized coal is dispersed particle consisted of raw coal, char and ash. Its behavior is described in the fixed coordinate system.

2) Raw coal can be expressed as $C_{p} H_{q} O_{r} N_{s}$, and the stoichiometric coefficient $p, q, r$ and $s$ are determined by using proximate analysis value and ultimate analysis value.

3) Devolatilization process is described by two competing reactions model. ${ }^{11-13)}$

4) Combustion rate of volatiles generated at above process is calculated by eddy dissipation model. ${ }^{8)}$

5) Char consists of only carbon, and its gasification rate is calculated by surface reaction model. ${ }^{4}$ )

6) Ash is non-reacting matter and the amount of that in a particle does not change.

Further, the considered chemical reactions are shown in Table 1.

Under the above assumptions, conservation equations of mass, momentum and energy are constructed for each phase. The equations for gas and pulverized coal are described in Eulerian coordinate system and they are dis-
Table 1. Chemical reactions (g: gas, s: coke, char)

\begin{tabular}{|l|l|}
\hline \multicolumn{1}{|c|}{ Gas-gas reactions } & \multicolumn{1}{c|}{ Gas-solid reactions } \\
\hline $\mathrm{CO}(\mathrm{g})+1 / 2 \mathrm{O}_{2}(\mathrm{~g}) \rightarrow \mathrm{CO}_{2}(\mathrm{~g})$ & $\mathrm{C}(\mathrm{s})+\mathrm{O}_{2}(\mathrm{~g}) \rightarrow \mathrm{CO}_{2}(\mathrm{~g})$ \\
\hline $\mathrm{H}_{2}(\mathrm{~g})+1 / 2 \mathrm{O}_{2}(\mathrm{~g}) \rightarrow \mathrm{H}_{2} \mathrm{O}(\mathrm{g})$ & $\mathrm{C}(\mathrm{s})+\mathrm{CO}_{2}(\mathrm{~g}) \rightarrow 2 \mathrm{CO}(\mathrm{g})$ \\
\hline Volatiles $(\mathrm{g})+\mathrm{O}_{2}(\mathrm{~g}) \rightarrow$ Products $(\mathrm{g})$ & $\mathrm{C}(\mathrm{s})+\mathrm{H}_{2} \mathrm{O}(\mathrm{g}) \rightarrow \mathrm{H}_{2}(\mathrm{~g})+\mathrm{CO}(\mathrm{g})$ \\
\hline
\end{tabular}

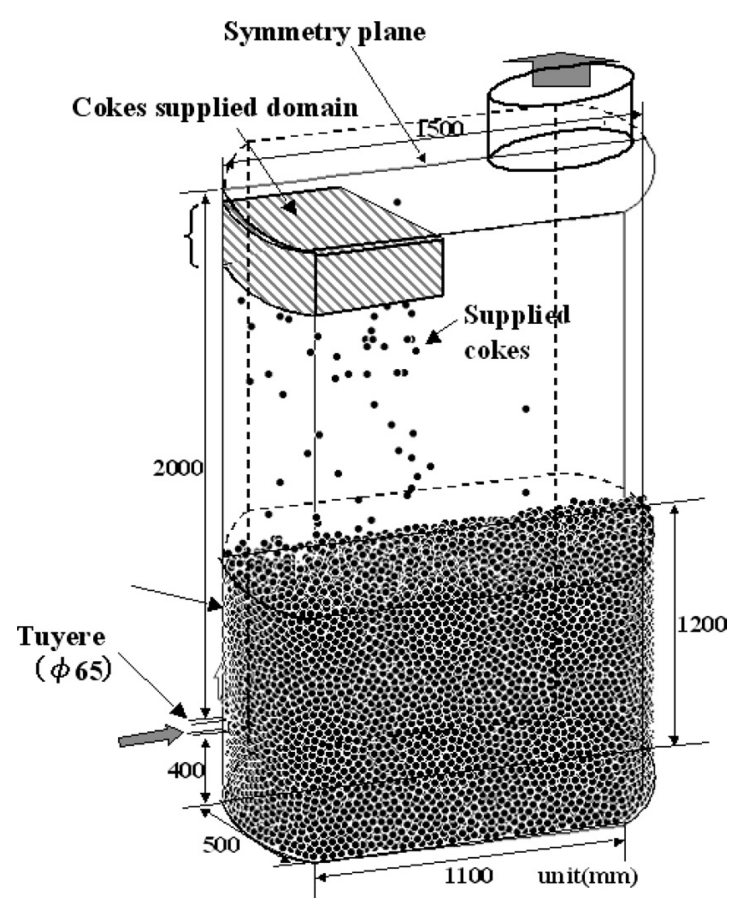

Fig. 1. Schematic figure of hot model.

cretized with the aid of FDM based upon $\mathrm{BFC}^{14)}$ (Boundary Fitted Coordinate). Additionally, flow analysis algorithm based on SOLA method ${ }^{15)}$ is adopted for the purpose of calculating the time marching solutions of their equations. With regard to coke phase, the basic equations described in Lagrangian coordinate system are constructed for respective coke particles. Their equations expressed in the form of ordinary differential equations are integrated in the time direction by use of Runge-Kutta method for mass balance equation, leap-flog method for momentum balance equation and trapezoid method for energy balance equation.

\subsection{Verification of Mathematical Model}

In order to verify the mathematical model, the numerical analysis for hot model test was performed. The schematic figure of hot model is shown in Fig. 1. The operational conditions are as follows; Blast volume is $700\left[\mathrm{Nm}^{3} / \mathrm{h}\right]$, Blast temperature is $800\left[{ }^{\circ} \mathrm{C}\right]$, and $\mathrm{O}_{2}$ enrichment is equal to $10\left[\mathrm{Nm}^{3} / \mathrm{h}\right]$. Further, this analysis was performed for both all cokes operation and PCI operation. The properties used in this simulation are shown in Tables $\mathbf{2}$ and $\mathbf{3}$.

Figure 2 shows the calculated and measured raceway shapes. Dotted line shows the raceway shapes obtained by the visual observation using optical fiber in hot model experiment. On the shape and size, the calculated raceway almost accords with the measured value. Raceway shell is shown in Fig. 3. The calculated shell is defined as the cloud, which is constituted of particles with the diameter less than $0.02[\mathrm{~m}]$ and with the local void fraction less than $0.4[-]$. Many coke particles contracted by gasification exist in the calculated shell. On the other hand, the photo- 
Table 2. Property of coke.

\begin{tabular}{|l|l|}
\hline Bulk density $\left[\mathrm{kg} / \mathrm{m}^{3}\right]$ & 1081 \\
\hline Compressive strength $[\mathrm{Pa}]$ & $5.0 \times 10^{7}$ \\
\hline Specific heat $[\mathrm{J} / \mathrm{kg} / \mathrm{K}]$ & $2.0 \times 10^{2}+2.0 \mathrm{~T}-1.0 \times 10^{-3} \mathrm{~T}^{2}+1.7 \times 10^{-7} \mathrm{~T}^{3}$ \\
\hline Thermal conductivity $[\mathrm{W} / \mathrm{m} / \mathrm{K}]$ & $\left(-7.6 \times 10^{-1}+6.3 \times 10^{-3} \mathrm{~T}\right)(1-\varepsilon)$ \\
\hline Shape factor $[-]$ & 0.7 \\
\hline Initial diameter $[\mathrm{m}]$ & 0.03 \\
\hline Friction coefficient $[-]$ & 0.3 \\
\hline Restitution coefficient $[-]$ & 0.9 \\
\hline Stiffness constant $[\mathrm{N} / \mathrm{m}]$ & $2 \pi \mathrm{R}_{1} \mathrm{R}_{2} /\left(\mathrm{R}_{1}+\mathrm{R}_{2}\right) \mathrm{S}_{\mathrm{c}} / 100$ \\
\hline
\end{tabular}

Table 3. Property of pulverized coal.

\begin{tabular}{|c|c|}
\hline Bulk density $\left[\mathrm{kg} / \mathrm{m}^{3}\right]$ & 1081 \\
\hline $\begin{array}{l}\text { Proximate analysis } \\
\text { [mass\%,dry base] }\end{array}$ & \begin{tabular}{|cccc} 
Moisture & Volatiles & Fixed Carbon & Ash \\
8.8 & 32.9 & 48.77 & 9.53 \\
\end{tabular} \\
\hline $\begin{array}{l}\text { Ultimate analysis } \\
\text { [mass\%] }\end{array}$ & $\begin{array}{|cccc|}\mathrm{C} & \mathrm{H} & \mathrm{O} & \mathrm{N} \\
74.99 & 5.11 & 8.88 & 1.63 \\
\end{array}$ \\
\hline Specific heat $[\mathrm{J} / \mathrm{kg} / \mathrm{K}]$ & $\begin{array}{l}\left\{\mathrm{Y}_{\text {Volatiles }}\left(73+55 \times 10^{-3} \mathrm{~T}-31 \times 10^{5} / \mathrm{T}^{2}\right) / 142\right. \\
+\mathrm{Y}_{\text {Fixed Carbon }}\left(4.1+1.0 \times 10^{-3} \mathrm{~T}-2.1 \times 10^{5} / \mathrm{T}^{2}\right) / 12 \\
\left.+\mathrm{Y}_{\text {Ash }}\left(11+8.2 \times 10^{-3} \mathrm{~T}\right) / 92\right\} \times 41.86\end{array}$ \\
\hline Shape factor [-] & 0.7 \\
\hline Initial diameter [m] & $7.4 \times 10^{-5}$ \\
\hline
\end{tabular}

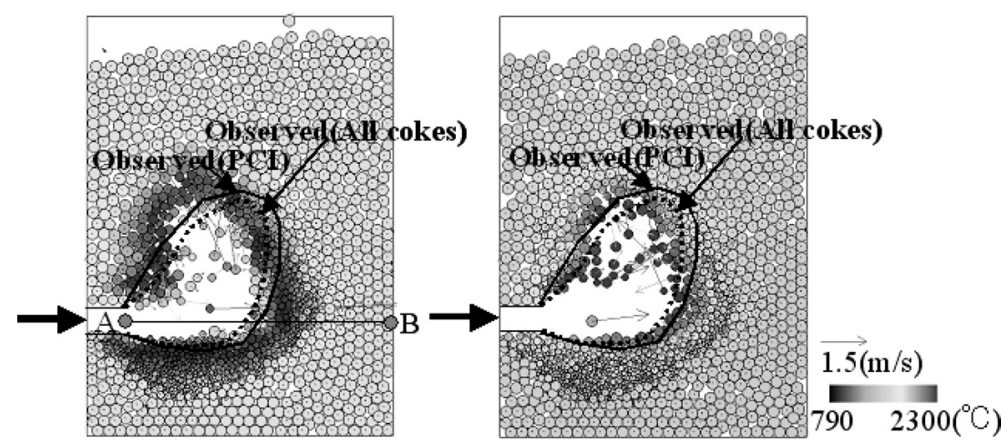

(a) All cokes

(b) PCI

Fig. 2. Raceway shapes.

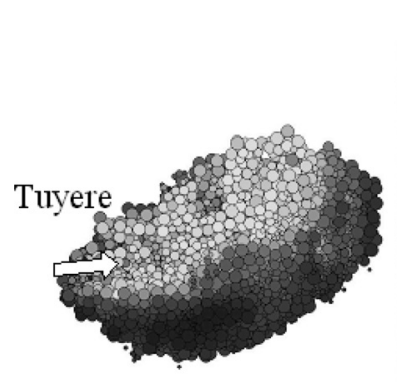

(a) Calculation

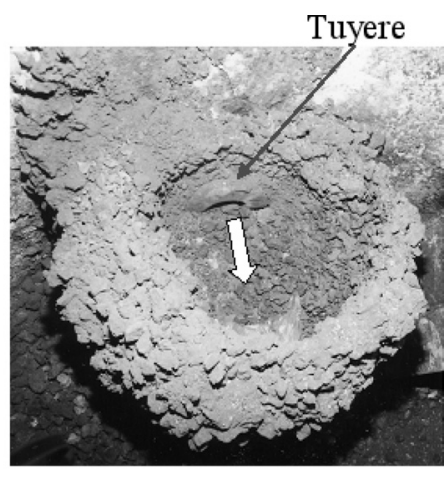

(b) Experiment

Fig. 3. Raceway shell (Bird nests).

graph of the shell was taken after the operation in hot model experiment. The calculation neglects the influence of melting ash, nevertheless the calculated shell has the structure similar to the shell obtained by experiment. This means that the movement of small coke particles contracted by gasification almost determines the formation of raceway shell. Small particles delivered by gas flow to the raceway boundary don't return inside raceway space and enter into the packed beds. Then, most of them lose the momentum by collision with coke in packed beds and accumulate on the surface domain of the packed beds with decreasing their mass by solution-loss reaction.

Figure 4 shows the distributions of gas compositions on the central axis of tuyere in all coke and PCI operations. In all cokes operation, the calculated results almost agree with the measured one. On the other hand, in PCI operation, calculated results don't agree with the measured so well, but there is the contradiction in mass balance of the measured value. Since it is difficult to measure the gas compositions inside and around raceway in PCI condition, it is consid-

ered that the measured value cannot be so trusted. Though the calculation accuracy is not exact in the current, this model has the sufficient accuracy in order to carry out the engineering examination.

\section{The Design of Appropriate Raceway for Innovative Blast Furnace}

In the innovative blast furnace to aim at great reduction of energy consumption, low temperature operation has to be performed. Therefore, the raceway needs to have large size and high reaction rate. In order to design the raceway satisfying the above-mentioned requirements, effects of temperature and composition of the blast gas on the controllability of raceway are investigated, and the raceway conditions in top gas recycling process which is one of the processes realizing highly efficient furnace are clarified.

\subsection{Influence of Blast Temperature and Compositions on Raceway Conditions}

The nitrogen enrichment is investigated as the method to change the compositions of blast gas.

Analysis conditions are shown in Table 4. The blast volume and the amount of nitrogen enrichment were determined under restricting that the bosh gas volume is kept constant. In this study, bosh gas is defined as the flowing out from the analysis domain.

Figure 5 shows the calculated raceway shapes. As the amount of nitrogen enrichment increases, the height of raceway tends to become small. It is because the gas temperature near the raceway shell becomes low and the gas volume flowing upward along the shell decreases. Moreover, when the blast temperature rises, the raceway depth expands slightly. The reason is because it enlarges the impact energy of the gas flow supplied from the tuyere. 


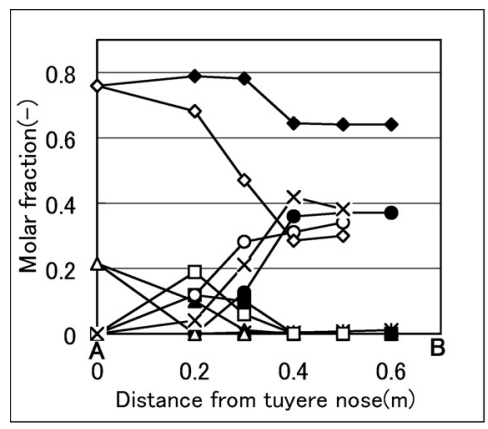

(a) Experiment

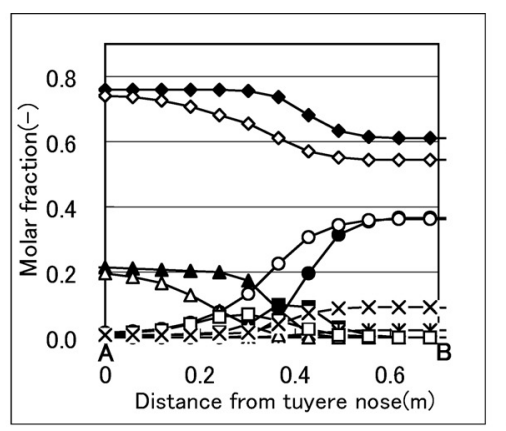

(b) Calculation

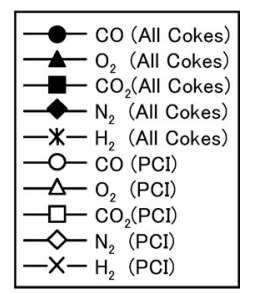

Fig. 4. Distributions of gas compositions on the central axis of tuyere.
Table 4. Analysis conditions.

\begin{tabular}{|c|cc|c|c|c|c|}
\hline Blast temp. & Concentration of & \multicolumn{5}{|c|}{ Flow rate $\left[\mathrm{Nm}^{3} / \mathrm{hr}\right]$} \\
\cline { 3 - 6 }$\left[{ }^{\circ} \mathrm{C}\right]$ & $\mathrm{O}_{2}[$ Vol\%] & $\mathrm{Air}$ & $\mathrm{O}_{2}$ & $\mathrm{~N}_{2}$ & Total \\
\hline 800 & 22 & 700.00 & 10.00 & 0.00 & 710.00 \\
\hline 800 & 15 & 538.51 & 0.00 & 215.40 & 753.91 \\
\hline 800 & 10 & 375.32 & 0.00 & 412.85 & 788.17 \\
\hline 1000 & 10 & 375.32 & 0.00 & 412.85 & 788.17 \\
\hline 1200 & 10 & 375.32 & 0.00 & 412.85 & 788.17 \\
\hline
\end{tabular}

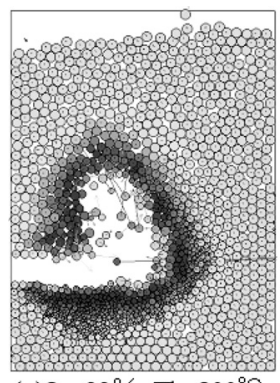

(a) $\mathrm{O}_{2}=22 \%, \mathrm{~Tb}=800^{\circ} \mathrm{C}$

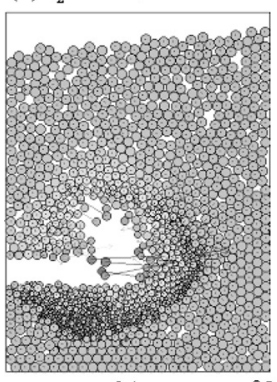

(d) $\mathrm{O}_{2}=10 \%, \mathrm{~Tb}=1000^{\circ} \mathrm{C}$

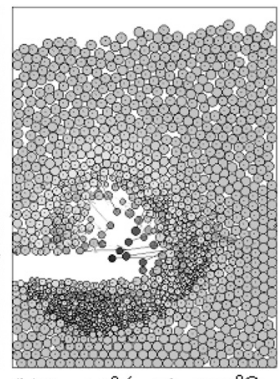

(b) $\mathrm{O}_{2}=15 \%, \mathrm{~Tb}=800^{\circ} \mathrm{C}$

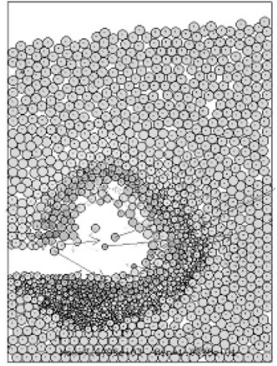

(e) $\mathrm{O}_{2}=10 \%, \mathrm{~Tb}=1200^{\circ} \mathrm{C}$

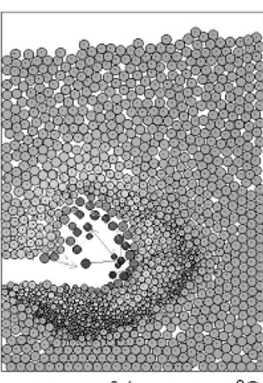

(c) $\mathrm{O}_{2}=10 \%, \mathrm{~Tb}=800^{\circ} \mathrm{C}$

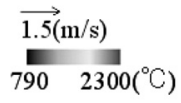

Fig. 5. Calculated raceway shapes $\left(\mathrm{O}_{2}: \mathrm{O}_{2}\right.$ concentration of blasting gas, $\mathrm{T}_{\mathrm{b}}$ : Blast temperature).

In order to realize the high efficient furnace, it is necessary that gas generating inside raceway spreads uniformly in the radial direction of the furnace and that the gas is supplied sufficiently to near the central axis of the furnace. On the other hand, the ventilation of the radial direction is affected considerably by the existence of raceway shell. Therefore, from the viewpoint of raceway shape, it is more desirable to enlarge the depth of raceway rather than the height. Hence, it seems to be effective in broadening raceway to enrich nitrogen and to increase the blast temperature.

Figure 6 shows the gas temperature distributions inside and around raceway. Figure 7 shows the gas temperature on the central axis of tuyere. Positions A and B on the horizontal axis of Fig. 7 correspond to those on the line in Fig. 6(e).
From these results, it can be found that nitrogen enrichment has the effect to lower the height of temperature peak inside and around raceway. In addition, the bosh gas temperature can be controlled easily by changing the blast temperature. Therefore, nitrogen enrichment can be said to be effective approach to form the uniform combustion zone with low temperature atmosphere.

The above results mean that the shape and size of raceway and the temperature inside and around raceway can be controlled by blast temperature and blast compositions. Since the raceway size is also influenced by blast volume, the desired raceway will be able to be realized when these blast conditions are determined.

\subsection{Evaluation of Raceway in Top Gas Recycling Process}

Top gas recycling is one of processes to reduce energy consumption and environmental loads. Especially, the remarkable process using this approach was proposed in the project on the innovation of ironmaking process by blast furnace for halving energy consumption and minimizing environmental influence. ${ }^{16)}$ The injection of reducing gas containing much hydrogen is effective to decrease $\mathrm{CO}_{2}$ emissions and reducing agent rate. ${ }^{16)}$

The concept of the proposed process is shown in Fig. 8. The process is characterized by (a) removing carbon dioxide in top gas, (b) blast of recycled gas and pure oxygen from tuyere and shaft part, and (c) plastic injection. Additionally, the blast gas from tuyere is supplied at room temperature. Table 5 shows the primary operation indices determined by mass and heat balance calculation using RIST diagram. ${ }^{16)}$ The productivity in this table means the operational upper limit. In the conventional process, the limit is determined by flooding condition. ${ }^{16)}$ On the other hand, in this gas recycling process, it is determined by fluidizing condition in top of the blast furnace. Since the pure oxygen blast is introduced in the recycling process, bosh gas volume becomes smaller than that in conventional process and flooding condition does not have determine the limit of production. Therefore, the gas recycling process has the advantage about not only reducing the $\mathrm{CO}_{2}$ emissions but also the enhancement of productivity or the downsizing of furnace.

However, since the blast conditions of this process quite differs from that of conventional process, raceway in this process are expected to be different considerably from the conventional process. Therefore, it is necessary to evaluate 


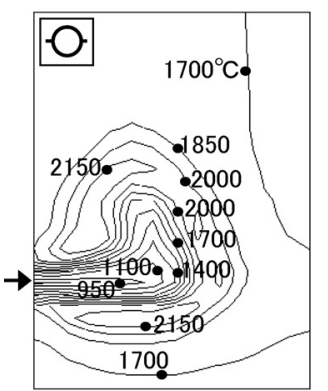

(a) $\mathrm{O}_{2}=22 \%, \mathrm{~T}_{\mathrm{b}}=800^{\circ} \mathrm{C}$

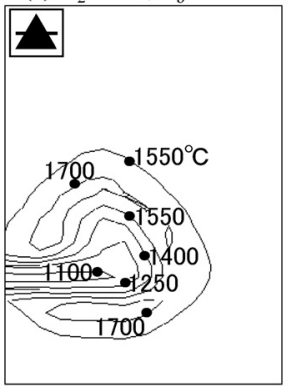

(d) $\mathrm{O}_{2}=10 \%, \mathrm{~T}_{\mathrm{b}}=1000^{\circ} \mathrm{C}$

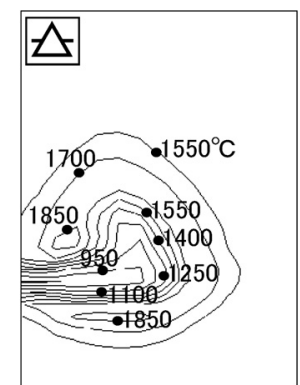

(b) $\mathrm{O}_{2}=15 \%, \mathrm{~T}_{\mathrm{b}}=800^{\circ} \mathrm{C}$

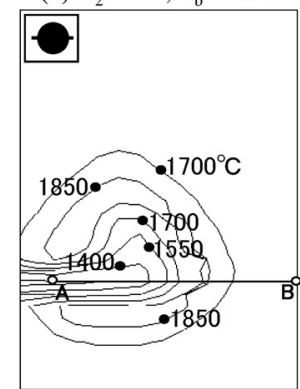

(e) $\mathrm{O}_{2}=10 \%, \mathrm{~T}_{\mathrm{b}}=1200^{\circ} \mathrm{C}$

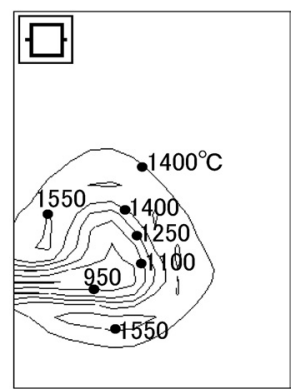

(c) $\mathrm{O}_{2}=10 \%, \mathrm{~T}_{\mathrm{b}}=800^{\circ} \mathrm{C}$

Fig. 6. Effect of blast conditions on gas temperature.

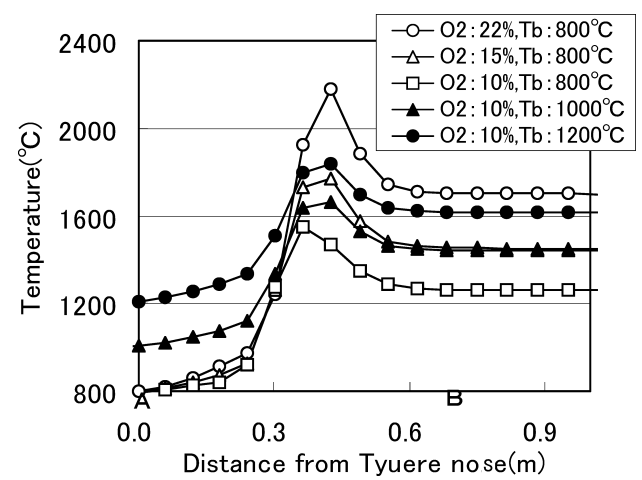

Fig. 7. Gas temperature distributions on the central axis of tuyere.

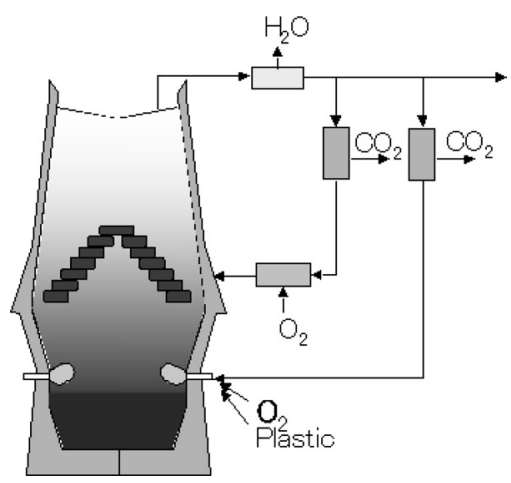

Fig. 8. Top gas recycling process.

not only mass and heat balance in the furnace but also raceway. Then, authors grasped the characteristics of the raceway in this process and evaluated whether it satisfies the raceway requirements for the novel blast furnace or not. In addition, the influence of plastic diameter on raceway was investigated.

Figures 9-11 show the calculated raceway shapes, gas temperature and gas flow velocity, respectively. Figures 12 and 13 show mass fractions of gaseous species $\left(\mathrm{CO}_{2}, \mathrm{H}_{2} \mathrm{O}\right)$ and the distributions of gas temperature and components on
Table 5. Primary operation indexes.

\begin{tabular}{|c|c|c|c|}
\hline \multirow{2}{*}{\multicolumn{2}{|c|}{\begin{tabular}{|l|} 
Inner volume $\left[\mathrm{m}^{3}\right]$ \\
\end{tabular}}} & Conventional & Top gas recycling \\
\hline & & 4288 & 4288 \\
\hline \multicolumn{2}{|l|}{ Production[t/d] } & 8576 & 15000 \\
\hline \multicolumn{2}{|l|}{ Productivity[t/dm $\left.{ }^{3}\right]$} & 2.0 & 3.5 \\
\hline \multirow{2}{*}{\multicolumn{2}{|c|}{$\begin{array}{c}\text { Blast volume }\left[\mathrm{Nm}^{3} / \mathrm{min}\right] \\
{\left[\mathrm{Nm}^{3} / \mathrm{t}\right]}\end{array}$}} & 5700 & 6333 \\
\hline & & 957 & 608 \\
\hline \multirow[t]{5}{*}{ Blast Composition [\%] } & $\mathrm{O}_{2}$ & 29.0 & 34.1 \\
\hline & $\mathrm{N}_{2}$ & 71.0 & 17.6 \\
\hline & $\mathrm{CO}$ & 0.0 & 30.0 \\
\hline & $\mathrm{CO}_{2}$ & 0.0 & 0.0 \\
\hline & $\overline{\mathrm{H}_{2}}$ & 0.0 & 18.3 \\
\hline \multicolumn{2}{|l|}{ Blast temperature $\left[{ }^{\circ} \mathrm{C}\right]$} & 1200 & 25 \\
\hline \multicolumn{2}{|c|}{ Pulverized coal injection rate $[\mathrm{kg} / \mathrm{t}]$} & 250 & 0 \\
\hline \multicolumn{2}{|c|}{ Plastic injection rate $[\mathrm{kg} / \mathrm{t}]$} & 0 & 100 \\
\hline \multicolumn{2}{|l|}{ Number of tuyere[-] } & 40 & 40 \\
\hline \multicolumn{2}{|l|}{ Diameter of tuyere [mm] } & 13 & 13 \\
\hline
\end{tabular}

the central axis of tuyere.

In Fig. 9, line $\mathrm{A}, \mathrm{A}^{\prime}$ and $\mathrm{B}$ express the raceway depth of each cases, which were calculated with the aid of the following relation formulae between raceway factor $R_{\mathrm{f}}$ and penetration factor $P_{\mathrm{f}}{ }^{17)}$ These formulae were obtained from the results of theoretical analysis and cold model experiment.

$$
\begin{aligned}
& P_{\mathrm{f}}=R_{\mathrm{f}}^{1 / 3} \text {. } \\
& P_{\mathrm{f}} \equiv L_{\mathrm{R}} / D_{\mathrm{T}} \\
& P_{\mathrm{f}} \equiv 1 / 2 \cdot \rho_{\mathrm{g}} \mathbf{U}_{\mathrm{g}}^{2} /\left(g \rho_{\mathrm{c}} d_{\mathrm{c}}\right)
\end{aligned}
$$

Here, the depth shown by line $\mathrm{A}$ and $\mathrm{A}^{\prime}$ is calculated under the assumption that the gas temperature used for evaluating gas density $\rho_{\mathrm{g}}$ is blast temperature. On the other hand, in case of Line $\mathrm{B}$, it is assumed to be theoretical frame temperature. The frame temperature should be used as the gas temperature in this case, since the blast gas burns in blow pipe.

From Fig. 9, it can be seen that the raceway depth in top gas recycling process is almost equivalent to that in conventional process, but the raceway height tends to reduce. From the viewpoint of supplying the gas uniformly inside blast 
ISIJ International, Vol. 44 (2004), No. 12

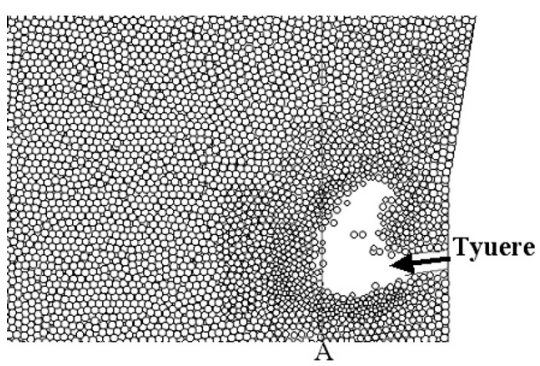

(a) Conventional

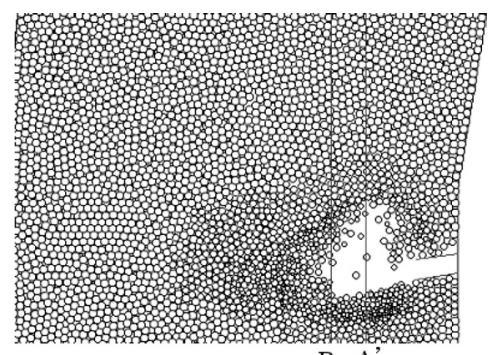

$\mathrm{B} \mathrm{A}^{\prime}$

(b) Top gas recycling $\left(\mathrm{D}_{\mathrm{pls}}=5.0 \mathrm{~mm}\right)$

Fig. 9. Calculated raceway shapes.

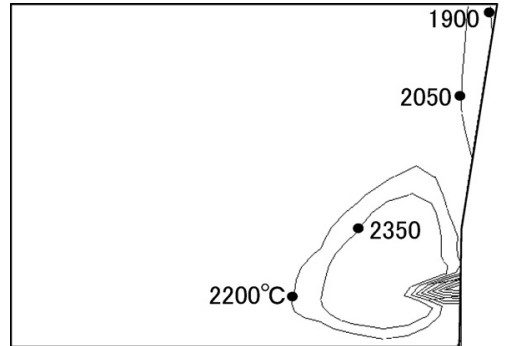

(a) Conventional

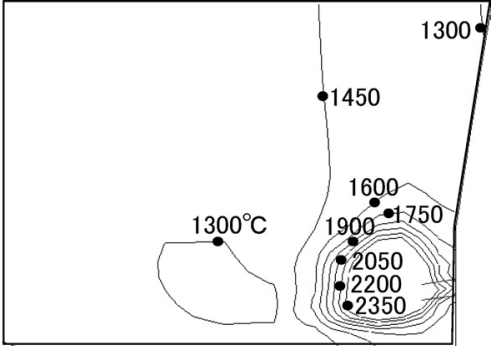

(b) Top gas recycling $\left(\mathrm{D}_{\mathrm{pls}}=5.0 \mathrm{~mm}\right)$

Fig. 10. Gas temperature.

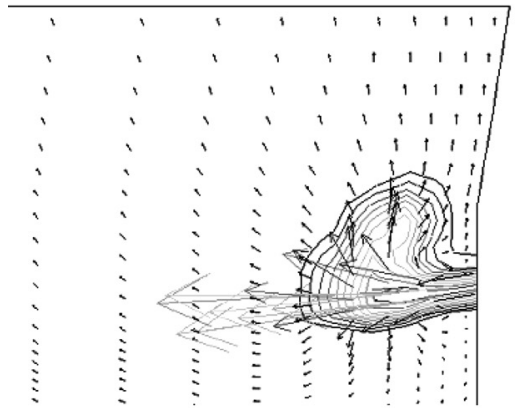

(a) Conventional

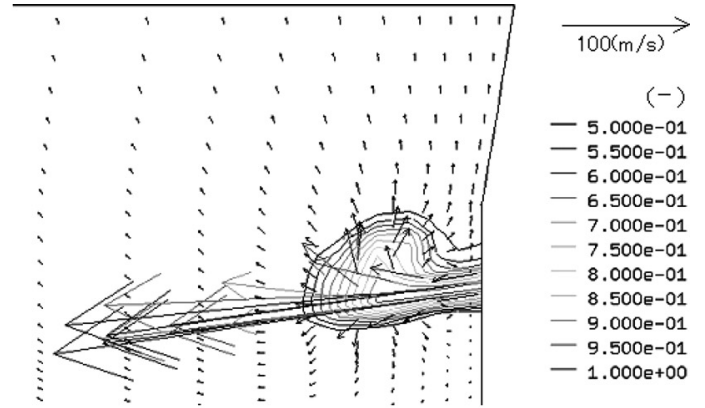

(b) Top gas recycling $\left(\mathrm{D}_{\mathrm{pls}}=5.0 \mathrm{~mm}\right)$

Fig. 11. Gas flow velocity.
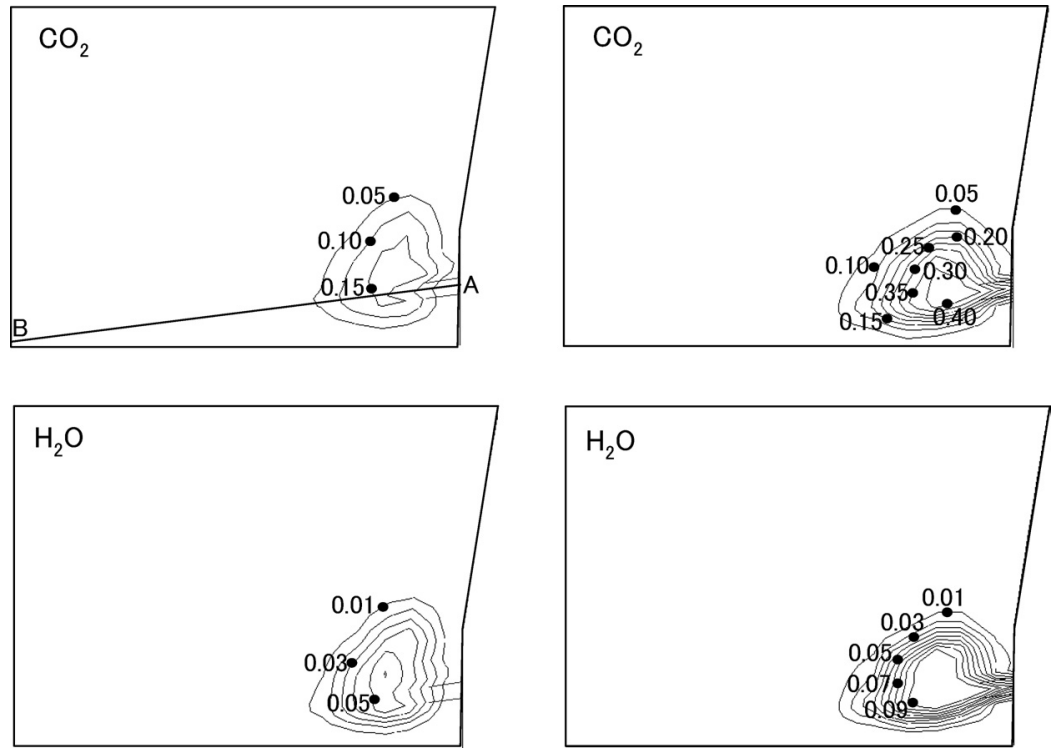

(a) Conventional

(b) Top gas recycling $\left(\mathrm{D}_{\mathrm{pls}}=5.0 \mathrm{~mm}\right)$

Fig. 12. Mass fraction of gas species. 


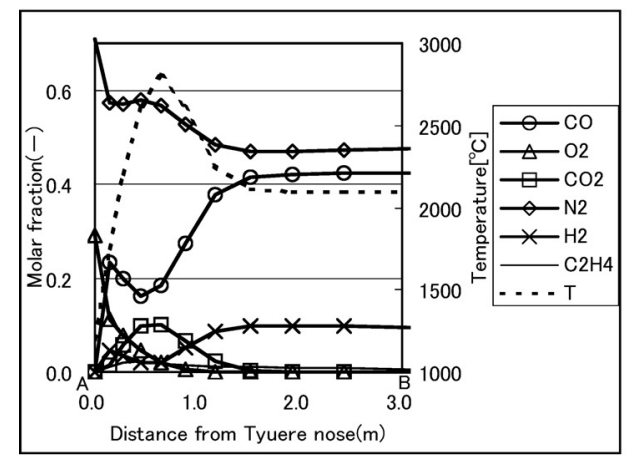

(a) Conventional

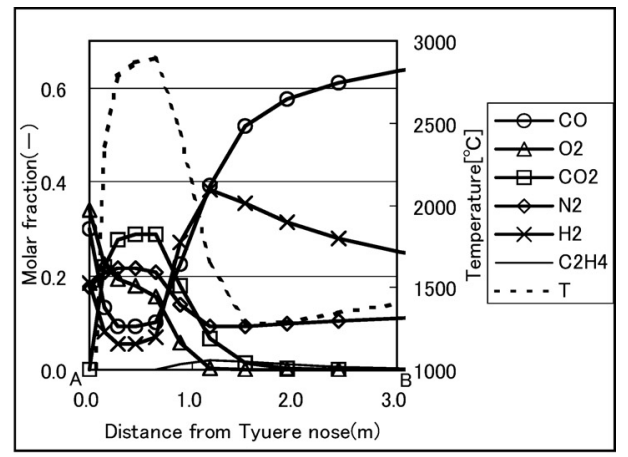

(b) Top gas recycling $\left(\mathrm{D}_{\mathrm{pls}}=5.0 \mathrm{~mm}\right)$

Fig. 13. Distributions of gas temperature and gas components on the central axis of tuyere.

furnace, the tendency is preferable. In this analysis conditions based upon Table 5, the blast temperature of recycling process is much lower than that of the conventional. Therefore, the volumetric flow rate is small and the raceway depth was expected to become too small as shown in line $\mathrm{A}^{\prime}$.

However, as shown in Figs. 12 and 13, gaseous combustion of $\mathrm{CO}$ and $\mathrm{H}_{2}$ in recycled gas already arises in the blow pipe. Therefore, the gas volume inside raceway increases considerably and the impact energy of gas arriving at the raceway boundaries becomes almost equivalent to that in conventional process. The raceway depth in this recycling process could be kept almost equal to that in the conventional and it is remarkable effect in this recycling process. Namely, this blasting method, which blows the combustibles in top gas together with pure oxygen into the furnace, has the ability to keep the raceway depth even if the blast is injected at room temperature.

By the way, from Figs. 10(b) and 13(b), it can be seen that there exits local low-temperature domain outside the raceway. Figures 14(a), 15(a) and 16(a) show gas temperature, plastic temperature and volume fraction of plastics, respectively, and in Fig. 16(a), the plastic flow vector is shown together. Their displayed domain corresponds to the whole analysis domain.

These figures show that the rise of plastic temperature is very slow and that the plastics tend to accumulate on and around the raceway shell. Since the temperature of accumulations is low, gas is cooled down by heat exchange with them. As a result, the local low-temperature domain shown in Fig. 14(a) is formed. Additionally, in this condition, the plastics were not discharged from the top of the furnace and accumulated in deadman and on the bottom part, which corresponds to the surface part of pig iron.

Next, the improvement of this non-uniform distribution of gas temperature was tried. As mentioned before, the formation of local low-temperature domain is caused by accumulation of plastic particles with low temperature. Then, their initial diameters were set to one tenth of the base condition $(=5[\mathrm{~mm}])$ and the effect of the diameter reduction was investigated.

The results are shown in Figs. 14(b), 15(b) and 16(b). When the diameter is reduced, the plastic temperature rises fast, and most of plastics are combusted and consumed inside raceway. Consequently, the accumulation near the shell is avoided, and the non-uniformity of the temperature distri-

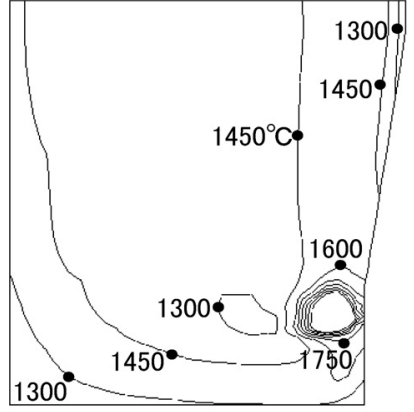

(a) $\mathrm{D}_{\mathrm{pls}}=5.0 \mathrm{~mm}$

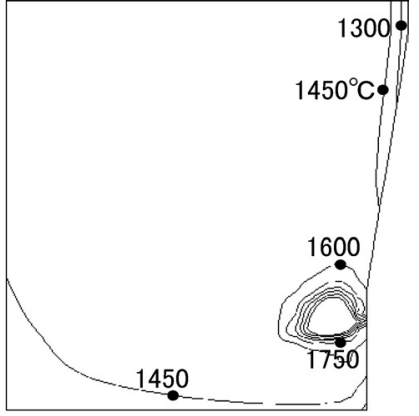

(b) $\mathrm{D}_{\mathrm{pls}}=0.5 \mathrm{~mm}$
Fig. 14. Effect of plastic diameter on gas temperature.

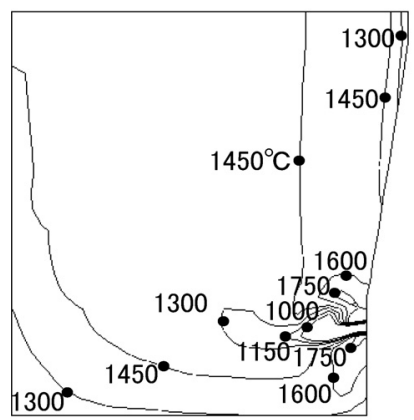

(a) $\mathrm{D}_{\mathrm{pls}}=5.0 \mathrm{~mm}$

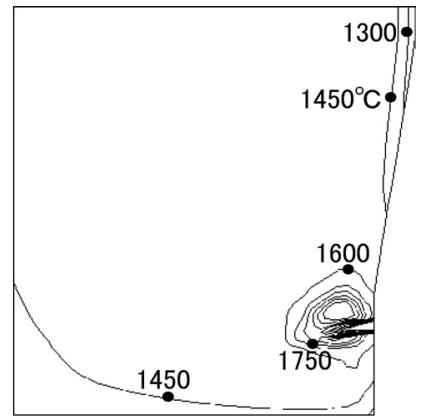

(b) $\mathrm{D}_{\mathrm{pls}}=0.5 \mathrm{~mm}$
Fig. 15. Effect of plastic diameter on plastic temperature.

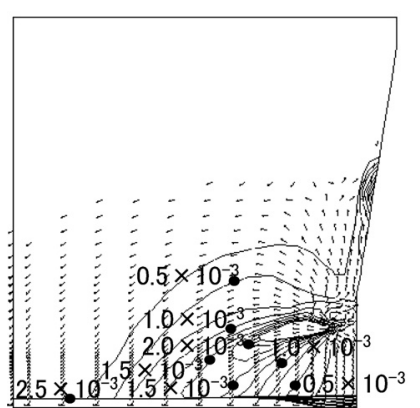

(a) $\mathrm{D}_{\mathrm{pls}}=5.0 \mathrm{~mm}$

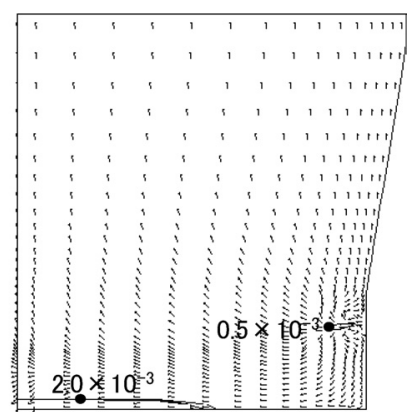

(b) $\mathrm{D}_{\mathrm{pls}}=0.5 \mathrm{~mm}$
Fig. 16. Effect of plastic diameter on volume fraction of plastics.

bution is improved greatly.

Additionally, in base conditions, since the unburned plastic particles got away from the upward gas stream and flow downwardly, they accumulated in the deadman and on the bottom part considerably. On the other hand, in this case 


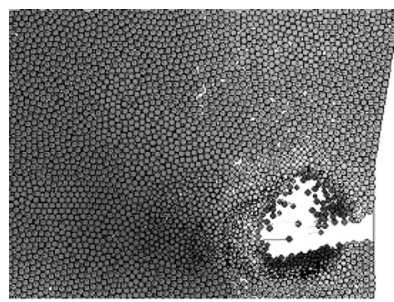

(a) $\mathrm{D}_{\mathrm{pls}}=5.0 \mathrm{~mm}$

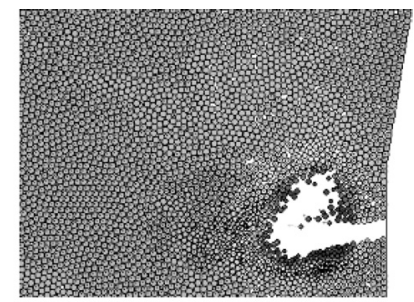

(b) $\mathrm{D}_{\mathrm{pls}}=0.5 \mathrm{~mm}$
Fig. 17. Calculated raceway shapes.

Table 6. Macro indexes to characterize raceway.

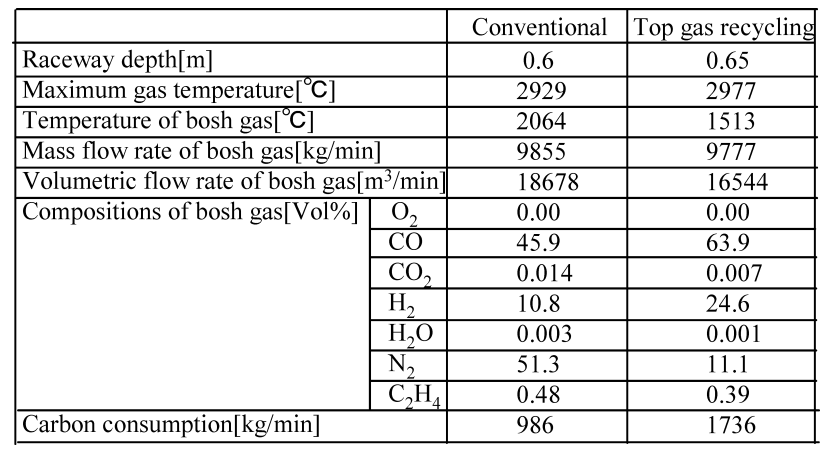

where the diameters are reduced, the amount of accumulations in the domain decreases greatly. It is because the unburned plastics are entrained by upward gas flow in addition to the improvement of the plastic combustion ratio inside raceway. The influence of the powder particle diameter on accumulation in the furnace lower part is also examined in another investigation. ${ }^{18)}$ It was pointed out in the study that heavy powders like fine coke accumulate in the deadman and deteriorate the permeability of deadman when their diameters are large. ${ }^{18)}$ In this calculation, the density of plastics is set to $960\left[\mathrm{~kg} / \mathrm{m}^{3}\right]$, which is almost equal to that of fine coke. Therefore, the reduction of plastics diameters has the effect not only to improve the temperature distribution of combustion field but also to enhance the permeability of deadman.

Figure 17 shows calculated raceway shapes. In case that the diameter of plastics is made small, the combustion ratio of plastics inside raceway rises and the gas volume inside raceway increases, and the raceway expands slightly.

Macro indices which characterize the raceway of each process are shown in Table 6. Here, the result of top gas recycling process corresponds to the case where the plastics diameters are reduced. In addition, carbon consumption in this table means the consumption rate of coke inside and around raceway, and it was calculated by summing up gasification rate of coke particles existing in the domain.

From theses results, it can be seen that the raceway in top gas recycling process has the following characteristics.

1) The raceway depth becomes a little larger.

2) The consumption rate of carbon increases greatly.

3) The temperature of bosh gas falls considerably and the volumetric flow rate becomes small relatively.

The increase in consumption rate of carbon is reasonable result. It is because the concentration of $\mathrm{O}_{2}$ in the blast gas is raised by use of pure oxygen, and because the blast volume is increased in this case for aiming at enhancement of production. Nevertheless, the volumetric flow rate of bosh gas is smaller than that in the conventional process with less production, and flooding conditions tends to be more relaxed. Since the blast in this recycling process is performed at room temperature, the temperature of bosh gas becomes low. Therefore, the volume of bosh gas decreases.

In addition, the above characteristics correspond to the raceway requirements already mentioned. Therefore, the raceway in this recycling process is appropriate for the innovative blast furnace with high efficiency. Additionally, since the raceway does not have disadvantage in comparison with that of the conventional, it seems that possibility of its realization is high.

\section{Conclusions}

For the purpose of reducing energy consumption and $\mathrm{CO}_{2}$ emissions, the design of combustion zone appropriate for the highly efficient blast furnace was tried with the aid of raceway mathematical model. In this work, the following results were obtained.

(1) The verification of the raceway mathematical model was performed for the hot model test. As a result, it was confirmed that the model could represent sufficiently the characteristics of raceway in all coke operation and PCI operation. In addition, the verification showed that the model has the ability to predict not only the raceway shape and the combustion state within raceway but also the raceway shell.

(2) The influence of blast temperature and blast compositions on raceway was investigated. Consequently, it was confirmed that the shape and size of raceway and its gas temperature could be controlled by these blast conditions. Additionally, it was shown that nitrogen enrichment is effective in forming the uniform combustion zone with low temperature atmosphere.

(3) The raceway in top gas recycling process was evaluated. As a result, it was confirmed that the raceway satisfied the requirements of combustion zone for the highly efficient blast furnace and that the possibility of the realization was high. In addition, it was shown that the raceway has the following characteristics.

- The volumetric flow rate of gas inside raceway increases because of gaseous combustion of top gas in blow pipe. Therefore, raceway size is enlarged even if blast temperature is low.

- With regard to the shape of raceway, the depth is expanded and the height is reduced. This tendency is preferable from the viewpoint of supplying the gas uniformly over the whole region of blast furnace.

- The volumetric flow rate of bosh gas decreases because the blast is performed at room temperature. Therefore, flooding conditions are relaxed and raceway is stabilized.

\section{Nomenclature}

$T$ :Temperature

$R_{1}, R_{2}:$ Particle radius

Sc : Compressive strength

$[\mathrm{Pa}]$

$D$ : Diameter of lump coke

$Y_{i}$ : Proximate analysis

$D_{\text {pls }}:$ Diameter of plastic particles

$P_{\mathrm{f}}:$ Penetration factor

[-]

$R_{\mathrm{f}}:$ Raceway factor 
$L_{\mathrm{R}}:$ Raceway depth

$D_{\mathrm{T}}:$ Tuyere diameter

$g$ : Gravity acceleration

$\mathbf{U}$ : Flow velocity

Greek symbol

$$
\begin{aligned}
& \varepsilon: \text { Void ratio } \\
& \rho \text { : Density }
\end{aligned}
$$

Subscripts

$$
\begin{aligned}
& \text { g : Gas } \\
& \text { c : Coke }
\end{aligned}
$$

\section{REFERENCES}

1) M. Kuwabara, Y. Hsieh and I. Muchi: Tetsu-to-Hagané, 66 (1980), 1918.

2) M. Hatano, K. Kurita and T. Tanaka: 42nd Ironmaking Proc., Iron Steel Soc. AIME, Pittsburgh, PA, (1983), 577.

3) H. Nogami, T. Miura and T. Furukawa: Tetsu-to-Hagané, 78 (1992), 1222.

4) J. He, M. Kuwabara, and I. Muchi: Tetsu-to-Hagané, 72 (1986), 1847.

5) H. Nogami and H. Yamaoka: Proc. of Int. Workshop on Science and Technology of Innovative Ironmaking for Aiming at Energy Half Consumption, ISIJ, Tokyo, (2003), 225.

6) H. Nogami, K. Takatani and H. Yamaoka: "Numerical analysis of blast furnace raceway using coupling model of Discrete Element Method and Finite Differencing Method", CAMP-ISIJ, 18 (2005), in press.

7) B. E. Launder and D. B. Spalding: Comput. Meth. Appl. Mech. Eng., 3 (1974).

8) B. E. Magnussen and B. H. Hjertager: Proc. 16th Symp. (Int.) Combust., The Combustion Inst., Pittsburgh, PA, (1976), 1657.

9) P. A. Cundall and O. D. L. Strack: Geotechnique, 29 (1979), No. 1, 47.

10) K. Hashimoto: Han-nou Kohgaku, Baifukan, Tokyo, (1979), 230.

11) H. Kobayashi, J. B. Howard and A. F. Sarofim: Proc. 16th Symp. (Int.) Combust. The Combustion Inst., Pittsburgh, PA, (1976), 411.

12) S. K. Ubhayakar, D. B. Stickler, C. W. von Rosenberg, Jr. and R. E. Gannon: Proc. 16th Symp. (Int.) Combust., The Combustion Inst., Pittsburgh, PA, (1976), 427.

13) J. M. Bergess, A. S. Jamaluddin, M. J. McCarthy, J. G. Mathieson, S. Nomura, J. S. Truelove and T. F. Wall: Proc. Joint Symp. of ISIJ and AIMM, ISIJ, Tokyo, (1983), 129.

14) K. Takatani: Tetsu-to-Hagané 74 (1988), 1546.

15) C. W. Hirt, B. D. Nichls and N. C. Romero: SOLA-A Numerical Solution Algorithm for Transient Fluid Flows, Los Alamos Sci. Lab., Los Alamos, (1975), LA-5852.

16) R. Murai, M. Sato and T. Ariyama: Proc. of Int. Workshop on Science and Technology of Innovative Ironmaking for Aiming at Energy Half Consumption, ISIJ, Tokyo, (2003), 205.

17) H. Yamaoka and K. Nakano: Tetsu-to-Hagané, 86 (2000), 733.

18) H. Nogami, P. R. Austin, J. Yagi and K. Yamaguchi: ISIJ Int., 44 (2004), 500 . 